\title{
Publication and citation patterns of Korean LIS research by subject areas
}

\author{
Kiduk Yang ${ }^{1 *}$, Jongwook Lee ${ }^{2}$, Wonchan Choi $^{3}$ \\ ${ }^{1}$ Department of Library and Information Science \\ Kyungpook National University, SOUTH KOREA \\ ${ }^{2}$ School of Information, College of Communication and Information \\ Florida State University, USA \\ ${ }^{3}$ School of Business, Worcester Polytechnic Institute, USA \\ e- mail: *kiyang@knu.ac.kr (corresponding author); \\ nadoopro@gmail.com; wchoi@wpi.edu
}

\begin{abstract}
Many researchers have suggested careful application of bibliometric indicators to research evaluation because of many factors including disciplinary norms that influence the publication and citation behaviors of researchers. Although some researchers have examined different bibliometric patterns across disciplines, relatively few scholars have focused on whether research performance should be evaluated in a uniform manner across research domains within a single discipline, especially in a multi-disciplinary fields such as library and information science (LIS). In order to ascertain whether such subject-specific differences exist in the LIS field, we conducted a bibliometric study that examined the publication and citation patterns across subject areas of LIS research in Korea. The analysis of our study data, which consisted of 6,838 citations to 1,986 domestic papers published between 2001 and 2010 by 163 LIS faculty members in Korea, revealed some evidence of bibliometric pattern differences across subject areas. In particular, we found that the authors in Bibliographic Studies, who were almost twice as productive as authors in other subject areas, received the lowest citation counts, which might be attributed to their different publishing and citing behaviors. Publication and citation patterns across subject areas of LIS papers and observation of the possible effect of sub-disciplinary culture on citing behaviors suggest the need for subject-specific assessment of multidisciplinary research discipline such as LIS. In future studies, we will investigate different publication and citation behaviors of authors by subject areas.
\end{abstract}

Keywords: Bibliometrics, publication count, citation count, Library and Information Science, subject area, South Korea

\section{INTRODUCTION}

Evaluation of faculty research in universities is one of the key elements in faculty recruitment, promotion and tenure, funding allocations, and award determinations (Abbasi, Altman, and Hwang 2010; De Bellis 2009). Two most widely used methods for evaluating faculty research are peer review and bibliometrics. Peer review, which is the qualitative evaluation of research by peers with expert knowledge of the field, has been the dominant method for faculty research evaluation (Brinn, Jones, and Pendlebury 2000). However, shortcomings of peer review, such as reviewer bias, inconsistency, and high resource intensity, gave rise to bibliometrics, which is a quantitative approach to research evaluation based on the analysis of publication statistics (De Bellis 2009). 
Bibliometrics, defined by Pritchard (1969, p. 349) as "the application of mathematics and statistical methods to books and other media of communication," rely on publication and citation data to analyze scholarly communication (Borgman 1990). Counting the number of publications is still the simplest and most common way to quantify research productivity, whereas citation indicators, such as citation count, impact factor, $h$-index, $g$-index, have often been used to assess the quality and impact of research (Cronin and Meho 2006; Osareh 1996; Smith 1981). In particular, many studies have demonstrated the validity of citation counts as an effective research performance measure, as they found statistically significant positive correlation between the citations and peer review ratings in disciplines such as physics, chemistry, mathematics, and library and information science (LIS) (Cronin 2005; Korevaar and Moed 1996; Li, et al. 2010; Norris and Oppenheim 2010; Rinia, van Leeuwen, van Vuren, and van Raan 1998; van Raan 2006).

At the same time, however, some researchers have pointed out the limitations of bibliometrics as a domain-specific measure, which is not optimal for comparing research performances across disciplines having different academic practices (Cronin 2005; Bornmann and Daniel 2008). In a similar context, an inter and multi-disciplinary field such as LIS (Saracevic 1999; Cronin and Meho 2008), which consists of researchers having diverse backgrounds (e.g., computer science, business and management, engineering, education, and arts and humanities) and research interests (Wu et al. 2012), may possess differences in publication and citation patterns across subject areas. Nevertheless, many researchers have examined publication and citation counts in LIS as a whole (Li et al. 2010; Norris and Oppenheim 2010), rather than looking into their potential differences by subject areas. In the current study, therefore, we conducted a bibliometric study that compared the publication and citation patterns across subject areas of LIS research in Korea. Specifically, we investigated the following research questions:

a) Which subject areas of LIS were productive (i.e., publication count) and influential (i.e., citation count) in South Korea?

b) Are there any differences in the publication and citation patterns across LIS subject areas in South Korea?

\section{LITERATURE REVIEW}

\section{Evaluative Bibliometric Studies in LIS}

Despite the conflicting findings regarding the validity of bibliometric measures for assessing research outcome, bibliometrics has remained popular among LIS researchers in evaluating scholarly work. For example, Budd and Seavey (1996) evaluated LIS research in the United States by counting publications and citations and found no significant difference in publication counts across academic faculty ranks, which directly contradicted the finding of an earlier study (Hayes 1983). In addition, Adkins and Budd (2006) attempted to measure the research effectiveness of faculty by examining their publications based on the assumption that faculty who published more are cited more, therefore more effective than faculty with fewer publications and citations. Their study, which used publication and citation data from Social Science Citation Index (SSCI) years 1999 to 2004 to rank the 20 most productive faculty members and programs, found a statistically significant difference in publication and citation counts by faculty rank.

Cronin and Meho (2006), found a positive relationship between citation count and $h$-index rankings of 31 influential information science faculty members. They interpreted the discrepancies between citation counts and $h$-indices in some cases as a discriminatory 
power of $h$-index and concluded that $h$-index could complement the citation count in measuring research impact.

Davarpanah and Aslekia (2008) conducted a descriptive study that examined publication counts by language, subject, institution, authorship, citation counts by self-citation and publication year of 894 articles published in 56 SSCl-indexed LIS journals between 2000 and 2004. The study revealed the top nations of LIS journal publishing to be the United States and United Kingdom, the most popular LIS topic to be communication and information technology, and that about a half of the authors in LIS cited their previous works while publishing their work as sole authors.

More recently, Walters and Wider (2015) analyzed the contributions of institutions, disciplines, and countries to LIS research based on the papers published in 31 LIS journals from 2007 to 2012. After categorizing authors into the nine groups (Librarian, LIS, Computer Science, Management, Communication, Other Social Sciences, Natural Sciences, Other Fields, Non-Academic) and journals into the six types (LIS Core, Practice-oriented, Information Processing \& Management, Management-oriented, Informetrics, other), Walters and Wider cross-tabulated papers by author and journal categories and then ranked the disciplines, countries, and departments using the publication count.

For LIS research in Korea, Yang and Lee (2012) conducted a bibliometric study that analyzed 2,401 publications from LIS faculties in Korea. The authors examined the research productivity of LIS schools in Korea based on various facets of publication data and found an increasing trend of collaboration, publications, and internationalization in the LIS field in Korea. In a follow-up study, Yang and Lee (2013) compared the LIS faculty rankings by publications, citations, $h$-index, and g-index and found that while publication counts correlate with citation counts for productive authors, no correlation was found between publication and citation counts of authors with the small number of publications.

To sum up, many researchers have tended to measure the quantity and quality of LIS research without consideration of the different research norms or patterns across LIS subdisciplines. Even though Davarpanah and Aslekia (2008) categorized subjects of the LIS papers analyzed in their study, they focused solely on the distributions of the publications by subjects, rather than looking into the potential impact of subject matter on citation patterns in LIS research, which is known as an inter- and multi-disciplinary field of study as mentioned above (Saracevic 1999; Cronin and Meho 2008). Our research is motivated by the question of whether research performance should be evaluated in a uniform manner across research domains, especially for multi-disciplinary fields such as LIS.

\section{Bibliometric Patterns across Disciplines/Sub-disciplines}

Scholars have examined the citations by research areas and found marked differences in citation counts across research areas. Brooks (1985), who reported different citation practices across disciplines, suggested that researchers in humanities tended to cite papers to persuade their arguments to others, while in science, the main reason for citing papers was to demonstrate currency. Vieira and Gomes (2010), who examined 226,166 journal articles published in 2004, reported different citation rates across disciplines of biology \& biochemistry, chemistry, mathematics, and physics. In their study, the average citation count of biology \&biochemistry was the highest (13.59), while mathematics had the lowest average citation count (3.22). Slyder et al. (2011) also observed a difference in the average citation counts between forestry and geography. In reaction to these study findings that highlighted the variations in citation patterns across disciplines, some scholars proposed 
the concept of relative citation indicators that can normalize the different citation practices in various disciplines (Radicchi, Fortunato and Castellano 2008; Castellano and Raddicchi 2009).

Some authors reported different bibliometric patterns across subject areas in LIS, for example, Blessinger and Hrycaj (2010) analyzed characteristics of 32 highly cited articles published in 10 influential LIS journals between 1968 and 2000. As part of their analyses, they checked the subject distribution of 32 articles by assigning them into five categories (Library Operations, Library/Information Science Profession, Publishing/Publishing Studies, Research in Librarianship/Users, Technology) and found that the majority (68\%) of the articles under examination belonged to research in Librarianship/Users, while a relatively smaller number of them were regarding practical topics such as Library Operation (8\%) and Library/Information Profession(2\%). The authors inferred the causes of difference in subject distribution as: (i) different citation activity across subject areas; (ii) existence of groundbreaking papers in certain areas; and (iii) different citability of papers across subject areas. Furthermore, Lee and Choi (2013) examined whether or not there were significant differences in citation rates by subject areas within Korean LIS. They found that papers addressing bibliographic topics tended to be less cited than those focusing on foundations of LIS, management and administration, library and information services, and information science. In this proposed study, we expanded Lee and Choi's research to investigate subject-specific publication and citation patterns in Korean LIS research as a first step for checking the validity of analyzing LIS research as a whole.

\section{METHODOLOGY}

\section{Data Collection}

For the study, we updated the dataset from an earlier study that analyzed 2,401 peerreviewed publications by 159 tenure-track professors from 34 LIS departments in South Korea (Yang and Lee 2012). While Yang and Lee's study used both international and domestic journal papers published by LIS faculty in Korea, this study analyzed only the domestic papers ${ }^{1}$ published by the LIS faculty, which consisted of 165 tenure-track professors as of May $2013^{2}$. International papers were excluded in order to filter out a typical citation patterns as well as to facilitate the subject classification of papers ${ }^{3}$. The bibliographic data for new faculty members were gathered from the Korea Citation Index (KCl: http://www.kci.go.kr) managed by National Research Foundation (NRF) of Korea. The citation data for all faculty members were updated using the $\mathrm{KCl}$ database, which has the largest coverage of citation data for academic papers in South Korea. If bibliographic data were unavailable from the $\mathrm{KCl}$, we used other data sources: (i) NAVER Academic Service (academic.naver.com), a scholarly publication search engine that provides academic services including citation information ${ }^{4}$, and (ii) Google Scholar (scholar.google.com), which provides citation information for the limited number of Korean journal articles. After

\footnotetext{
${ }^{1}$ It refers to the papers published in Korean journals by the authors affiliated with Korean universities.

${ }^{2}$ In the updated dataset, the number of faculty members increased from 159 to 165 due to 17 new faculty hires and 11 faculty retirements.

${ }^{3} \mathrm{~A}$ prior study by Lee and Yang (2011) found different publication and citation patterns between domestic and
international papers authored by Korean LIS faculty members.
} ${ }^{4}$ NAVER Academic Service (NAS) is a component of NAVER, which is the most popular search engine in Korea. Although the NAS coverage of citation data is smaller than that of $\mathrm{KCl}, \mathrm{NAS}$ contains data not indexed by $\mathrm{KCl}$.

Page | 70 
comparing citation counts from NAVER and Google Scholar, we chose greater counts among the two services. As a result, the number of unique papers, excluding the duplications created by collaborations among faculty members, was 1,986 , and the total number of citations to the papers was6, 838 as of Dec. 2015.

\section{Data Coding}

After collecting the domestic publication data from Korean LIS faculty for the past decade (2001-2010), two of the authors with backgrounds in Korean LIS literature analyzed the article titles to manually assign subject categories to 1,986 publications. From the subject classification schemes for LIS research, which have been proposed by researchers (e.g., Jarvelin and Vakkari 1990; Oh 2005; Park and Song 2013)and institutions (e.g., ALISE's LIS Research Areas Classification Scheme), we chose Park and Song's (2013) classification scheme, which is an extended version of Oh's (2005) scheme, because it is customized for Korean LIS research. Park and Song's scheme consists of 10 key subject areas: (1) Foundations of LIS (e.g., history, research methods, librarianship), (2) Library Building \&Facilities, (3) Library Structure (e.g., library/information policy, library collaboration, resource sharing), (4) Management and Administration (e.g., planning, personnel, collection development), (5) Library \&Information Services (e.g., types of libraries, reading and information literacy, service evaluation), (6) Information Organization (e.g., classification, cataloging, representation), (7) Information Science (e.g., bibliometrics, information system and retrieval, user studies)(8) Bibliographic Studies (e.g., old and rare books), (9) Publishing (e.g., print and digital publishing), and (10) Record Management (e.g., management of government material).

To increase reliability of subject assignment, the subject coders first engaged in a training session with a sample of 100 items, where they discussed the coding guidelines to adjudicate the discrepancies in coding results. After the training session, the coders individually assigned the subjects to the 1,986 articles by analyzing the titles. The intercoder reliability was Kappa $=0.813$ with $p<.001$, achieving the "almost perfectly agreed" reliability based on the rule of thumb by Landis and Koch (1977). Disagreements in the subject classification were resolved through discussions and the reconciled result was used for the data analysis.

\section{Data Analysis}

The publication, citation, and author counts were examined by year to identify the overall trend of KLIS faculty research and by subject areas to discover any subject-specific patterns. In particular, the author count in subject areas, which can reflect popularity of the areas, was used to figure out the average productivity and impact of subject areas. After analyzing citation, publication, and author counts by year and subject area, we crossmapped the data by year and subject area to ascertain subject-specific trends. A nonparametric (i.e., Kruskal-Wallis $\mathrm{H}$ test) statistical analysis was used to check the differences in citation patterns across subject areas. The study data was also examined by two fiveyear time frames (i.e., 2001-2005 and 2006-2010) so as to better understand the changing patterns of research.

\section{FINDINGS}

\section{Publication, Citation, and Author Counts by Year}

To get a general overview of Korean LIS research for the study period of 2001 to 2010, we first examined the numbers of publications, citations, and authors (Table 1). Overall, 176 
faculty members produced 2,351 unique papers during the study period of 10 years, which were cited 9,922 times. When the study data was restricted to domestic journal articles published by active faculty members for the purpose of subject-specific analysis, counts were reduced to 6,838 citations of 1,986 domestic papers published by 163 authors ${ }^{5}$.

Figure 1, which plots the numbers of publications, citations, and authors (i.e., number of faculty members who had authored or co-authored at least one paper) by year, displays temporal changes in productivity, impact, and popularity of domestic KLIS research. At first glance, the number of publications and the number of authors, each with a generally increasing pattern, suggest an increasing trend in research productivity and popularity, while the number of citations with a spike in 2007 suggests a research impact pattern incongruent with productivity. Such incongruity between research productivity and impact may be attributed to the citation lag and the incomplete status of data source at the time of data collection.

Table 1: Publication, citation, and author counts by year

\begin{tabular}{l|rrrrrrrrrrr}
\hline & 2001 & 2002 & 2003 & 2004 & 2005 & 2006 & 2007 & 2008 & 2009 & 2010 & Total \\
\hline pcnt $^{1}$ & 127 & 149 & 158 & 193 & 196 & 199 & 216 & 234 & 269 & 245 & 1986 \\
ccnt $^{2}$ & 557 & 439 & 453 & 570 & 774 & 791 & 943 & 892 & 783 & 636 & 6838 \\
aucnt $^{3}$ & 79 & 88 & 90 & 98 & 104 & 99 & 102 & 115 & 114 & 111 & 163 \\
\hline
\end{tabular}

${ }^{1}$ pcnt $=$ number of unique publications

${ }^{2} \mathrm{ccnt}=$ number of unique citations

3aucnt $=$ number of unique authors (i.e., faculty who published)

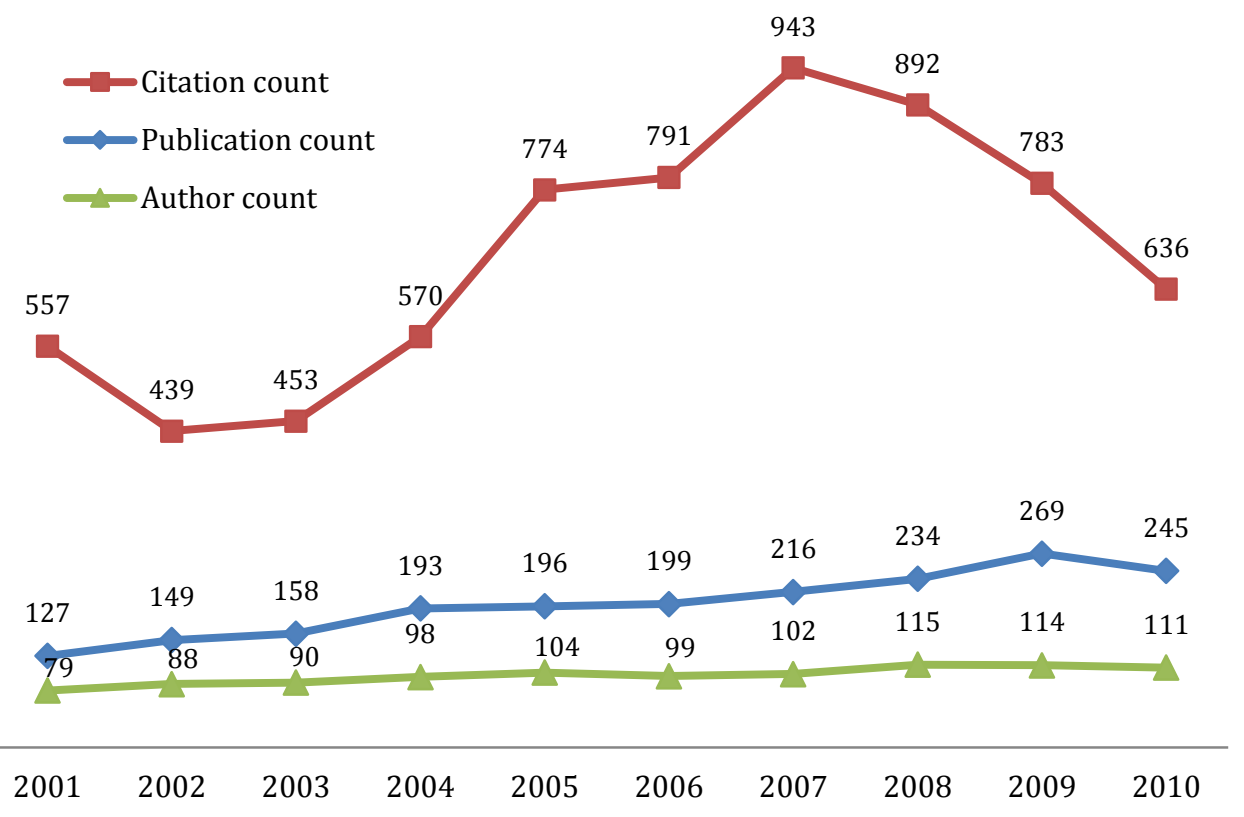

Figure 1: Publication, citation \& author counts by year ${ }^{5}$ Two of 165 active faculty members did not publish any articles in domestic journals at the time of data
collection. 


\section{Author, Publication, and Citation Counts by Subject Areas}

Author Count. Based on the number of authors in subject areas (Table2), the most popular subject area appears to be Information Science, where a majority of faculty authors (121 out of 163) published at least one paper, followed by Library \& Information Services (100).

To assess the change in popularity over time, we examined the unique number of authors who published (i.e., aucnt) and the average number of aucnt per year (i.e., avg_aucnt) in 2001-2005 and 2006-2010 (Table 2). According to the aucnt differences between the first and second five-year periods, Library Structure with $89 \%$ (17 authors) increase has the highest gain in popularity. The avg_aucnt shows Library \& Information Services and Library Structure doubling the average author counts in the second five years. Though Publishing doubled and Library Building \& Facilities increased its avg aucnt count by $67 \%$ in the second five years, the actual numbers of avg_aucnt increase are too small ( 0.2 and 1.2$)$ to be meaningful. Unique and average author counts in five-year periods point to the rising popularities of Management and Administration, Library \& Information Services, and Library Structure that are distinct from mostly stable popularity patterns of the other subject areas. Such trends reflect the growing interests in the research areas that cover the service and organizational aspects of LIS in Korea.

Table 2: Author statistics by subject areas

\begin{tabular}{|c|c|c|c|c|c|c|c|c|c|c|c|}
\hline \multirow{2}{*}{$\begin{array}{l}\text { Subject } \\
\text { Areas }\end{array}$} & \multicolumn{6}{|c|}{ aucnt $^{1}$} & \multicolumn{5}{|c|}{ avg_aucnt ${ }^{2}$} \\
\hline & \multicolumn{2}{|c|}{ '01-'05 '06-'10 } & \multicolumn{2}{|c|}{$\Delta(\%)$} & $\cap(\%)^{3}$ & $\begin{array}{c}\text { All } \\
\text { years }\end{array}$ & '01-'05 & '06-'10 & $\Delta$ & (\%) & $\begin{array}{c}\text { All } \\
\text { years }\end{array}$ \\
\hline BIB & 24 & 24 & 0 & $(0 \%)$ & 21 (78\%) & 27 & 15.2 & 15.6 & 0.4 & $(3 \%)$ & 15.4 \\
\hline FND & 47 & 69 & 221 & (47\%) & $29(33 \%)$ & 87 & 16.2 & 21.0 & 4.8 & $(30 \%)$ & 18.6 \\
\hline INS & 88 & 90 & 2 & $(2 \%)$ & $57(47 \%)$ & 121 & 40.2 & 41.6 & 1.4 & (3\%) & 40.9 \\
\hline IOR & 46 & 56 & $10 !$ & (22\%) & $26(34 \%)$ & 76 & 19.2 & 22.4 & 3.2 & (17\%) & 20.8 \\
\hline LBD & 9 & 13 & & (44\%) & $4(22 \%)$ & 18 & 1.8 & 3.0 & 1.2 & $(67 \%)$ & 2.4 \\
\hline LST & 19 & 36 & 17( & (89\%) & $5(10 \%)$ & 50 & 5.0 & 10.8 & 5.8 & (116\%) & 7.9 \\
\hline LSV & 52 & 82 & 301 & (58\%) & 34 (34\%) & 100 & 16.4 & 34.4 & 18.0 & $(110 \%)$ & 25.4 \\
\hline MNG & 47 & 64 & 17 & (36\%) & $28(34 \%)$ & 83 & 16.0 & 24.0 & 8.0 & (50\%) & 20.0 \\
\hline PUB & 1 & 1 & 0 & $(0 \%)$ & $0 \quad(0 \%)$ & 2 & 0.2 & 0.4 & 0.2 & $(100 \%)$ & 0.3 \\
\hline $\mathrm{RCM}$ & 13 & 24 & 11 & (85\%) & $6(19 \%)$ & 31 & 6.2 & 8.2 & 2.0 & (32\%) & 7.2 \\
\hline Total & 141 & 150 & 9 & $(6 \%)$ & $128(79 \%)$ & 163 & 136.4 & 181.4 & 45.0 & $(33 \%)$ & 158.9 \\
\hline \multicolumn{4}{|c|}{$\begin{array}{l}\text { BIB: Bibliographic Studies } \\
\text { IOR: Information Organization } \\
\text { LSV: Library \& Information Services } \\
\text { RCM: Record Management }\end{array}$} & $\begin{array}{l}\text { FND: } \\
\text { LBD: } \\
\text { MNE }\end{array}$ & $\begin{array}{l}\text { Foundations o } \\
\text { Library Buildin } \\
\text { : Managemen }\end{array}$ & $\begin{array}{l}\text { of LIS } \\
\text { ig \& Facili } \\
\text { it and Adn }\end{array}$ & $\begin{array}{l}\text { ies } \\
\text { inistration }\end{array}$ & $\begin{array}{l}\text { INS: I } \\
\text { LST: L } \\
\text { PUB: }\end{array}$ & $\begin{array}{l}\text { Informa } \\
\text { Library } \\
\text { Publisł }\end{array}$ & $\begin{array}{l}\text { nation Scie } \\
\text { y Structure } \\
\text { shing }\end{array}$ & $\begin{array}{l}\text { ence } \\
\text { e }\end{array}$ \\
\hline \multicolumn{12}{|c|}{$\begin{array}{l}{ }^{1} \text { aucnt }=\text { number of unique authors (i.e } \\
2 \text { avg_aucnt }=\text { average aucnt per year }\end{array}$} \\
\hline
\end{tabular}

The overlap column (i.e., column $\cap$ ) in Table 2 highlights yet another subject-specific characteristic in authorship. The overlap, computed by subtracting aucnt for all years from the sum of 2001-2005 and 2006-2010 aucnts, reflects the degree of new authorship, where $0 \%$ overlap signifies all new authors and $100 \%$ overlap means no new authors in the second five years. Bibliographic Studies with $78 \%$ overlap may be an evidence of a wellestablished research area with a core set of authoritative faculty authors or a stagnant research area.

Publication count. Table 3 shows the distribution of publication and author counts by ten subject areas. According to publication counts over the ten-year time period, Information 
Science has consistently been the most productive subject area, while the second most productive area has changed between several subject areas. In terms of publication count differences between time periods, Library Structure (113\%), Library \& Information Services (129\%) and Management and Administration (67\%) show highest increases over time ${ }^{6}$, in accordance with the popularity trend of those subject areas shown in the previous section.

For a given subject area, apr(au), which estimates the average productivity of an author with the sum of authors' publication counts divided by the number of authors, can be regarded as a measure of research productivity that takes into consideration the number of faculty authors as well as the number of publications in that subject area.

Table 3: Publication and author counts by subject areas

\begin{tabular}{|c|c|c|c|c|c|c|c|c|c|c|c|}
\hline \multirow[b]{2}{*}{ Subject } & \multicolumn{4}{|c|}{ pcnt $^{1}$} & \multirow{2}{*}{$\begin{array}{l}\text { aucnt }^{2} \\
\text { All } \\
\text { years }\end{array}$} & \multicolumn{6}{|c|}{$\operatorname{apr}(\mathrm{au})^{3}$} \\
\hline & $\begin{array}{l}\text { '01- } \\
\text { '05 }\end{array}$ & $\begin{array}{l}\text { '06- } \\
\text { '10 }\end{array}$ & $\Delta(\%)$ & $\begin{array}{c}\text { All } \\
\text { years }\end{array}$ & & $\begin{array}{l}01- \\
\text { '05 }\end{array}$ & $\begin{array}{l}\text { '06- } \\
\text { '10 }\end{array}$ & $\Delta$ & $(\%)$ & $\begin{array}{c}\text { All } \\
\text { years }\end{array}$ & (SD) \\
\hline $\mathrm{BIB}$ & 127 & 157 & $30(24 \%)$ & 284 & 27 & 5.29 & 6.71 & 1.42 & $(27 \%)$ & 10.67 & $(9.50)$ \\
\hline FND & 89 & 119 & 30 (34\%) & 208 & 87 & 1.98 & 1.97 & -0.01 & (0\%) & 2.63 & $(2.25)$ \\
\hline INS & 251 & 297 & 46 (18\%) & 548 & 121 & 3.19 & 3.70 & 0.51 & $(16 \%)$ & 5.07 & $(5.20)$ \\
\hline IOR & 118 & 140 & 22 (19\%) & 258 & 76 & 2.78 & 2.84 & 0.06 & $(2 \%)$ & 3.78 & (4.51) \\
\hline LBD & 10 & 17 & 7 (70\%) & 27 & 18 & 1.33 & 1.54 & 0.21 & $(15 \%)$ & 1.78 & $(1.20)$ \\
\hline LST & 23 & 49 & $26(113 \%)$ & 72 & 50 & 1.37 & 1.83 & 0.46 & $(34 \%)$ & 1.84 & $(1.60)$ \\
\hline LSV & 83 & 190 & 107 (129\%) & 273 & 100 & 1.67 & 2.63 & 0.96 & $(57 \%)$ & 3.03 & $(2.52)$ \\
\hline MNG & 87 & 145 & $58(67 \%)$ & 232 & 83 & 1.91 & 2.67 & 0.76 & $(40 \%)$ & 3.14 & $(3.34)$ \\
\hline PUB & 1 & 2 & 1 (100\%) & 3 & 2 & 1.00 & 2.00 & 1.00 & $(100 \%)$ & 1.50 & $(0.71)$ \\
\hline $\mathrm{RCM}$ & 34 & 47 & 13 (38\%) & 81 & 31 & 3.00 & 2.25 & -0.75 & $(-25 \%)$ & 3.00 & (3.04) \\
\hline Total & 823 & 1163 & 340 (41\%) & 1986 & 163 & 6.27 & 8.79 & 2.52 & $(40 \%)$ & 13.51 & $(10.58)$ \\
\hline \multicolumn{4}{|c|}{$\begin{array}{l}\text { BIB: Bibliographic Studies } \\
\text { IOR: Information Organization } \\
\text { LSV: Library \& Information Services } \\
\text { RCM: Record Management }\end{array}$} & \multicolumn{4}{|c|}{$\begin{array}{l}\text { LBD: Library Building \& Facilities } \\
\text { MNG: Management and Administration }\end{array}$} & \multicolumn{3}{|c|}{$\begin{array}{l}\text { LST: Library Structure } \\
\text { PUB: Publishing }\end{array}$} & \\
\hline $\begin{array}{l}{ }^{1} \text { pcnt }=r \\
2 \text { aucnt }= \\
{ }^{3} \text { apr(au) }\end{array}$ & umber & $\begin{array}{l}\text { of unique } \\
\text { of uniqu } \\
\text { ge produ }\end{array}$ & $\begin{array}{l}\text { publications } \\
\text { le authors (i.e } \\
\text { ctivity of an at }\end{array}$ & e. I deul & Tus & hed) & & & & & \\
\hline
\end{tabular}

According to this measure, Bibliographic Studies was the most productive area with 10.67 papers per author, followed by Information Science (5.07 papers). The marked high standard deviation (SD) of apr(au) for Bibliographic Studies reflects a large variability in research productivity among authors in that subject area. As a matter of fact, Bibliographic Studies in Korea is dominated by a handful of renowned scholars whose productivity far overshadows other researchers in the field. In light of the fact that publication frequency tends to be skewed, quartiles were charted in a box-and-whisker plot to confirm the findings. Figure 2, which displays inter quartile range (box) with minimum and maximum values (whisker), also showed Bibliographic Studies with the highest median value and the largest dispersion.

\footnotetext{
${ }^{6}$ Library Building \& Facilities increased its publication count by $70 \%$ and Publishing by $100 \%$ in the second fiveyear period, but the increases were too small in magnitude (7 papers by 4 authors and 1 paper by 1 author) to be considered as subject areas with high increases in productivity or popularity.
} 


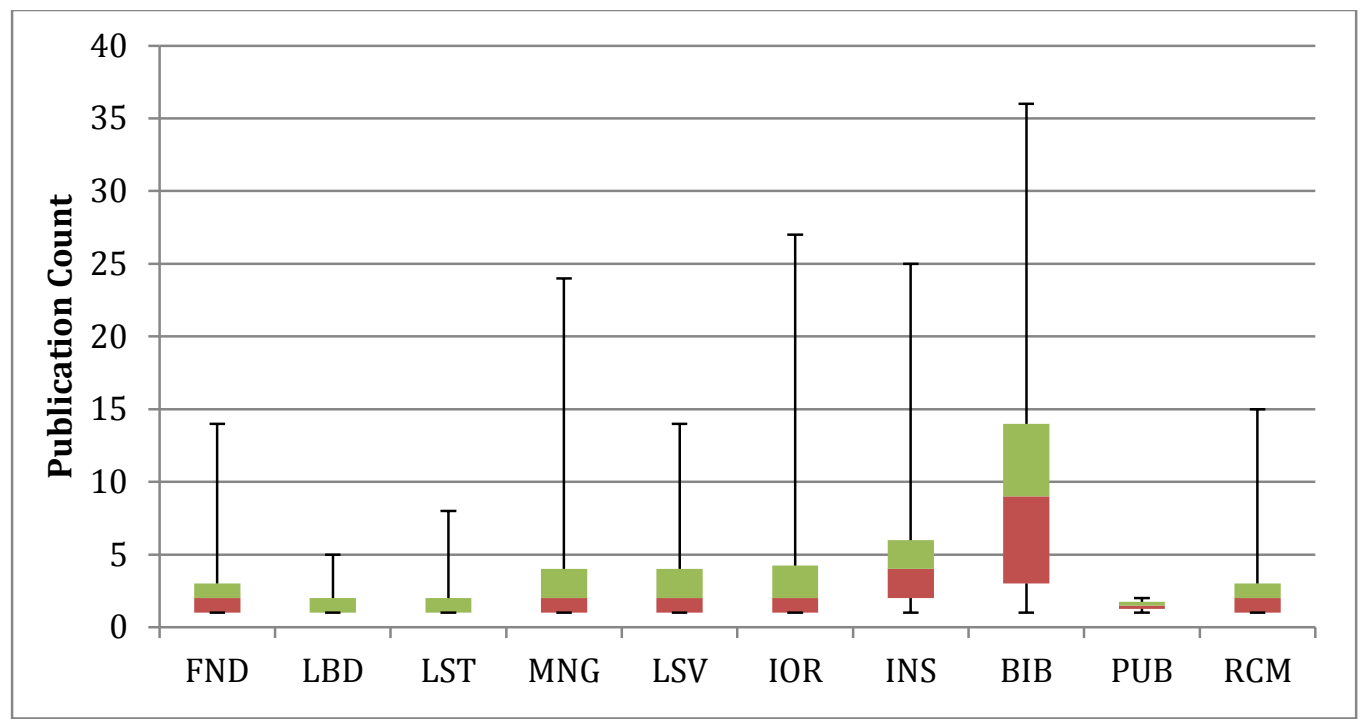

Figure 2. Publication counts by subject areas

Table 4: Subject area rankings by author and publication counts

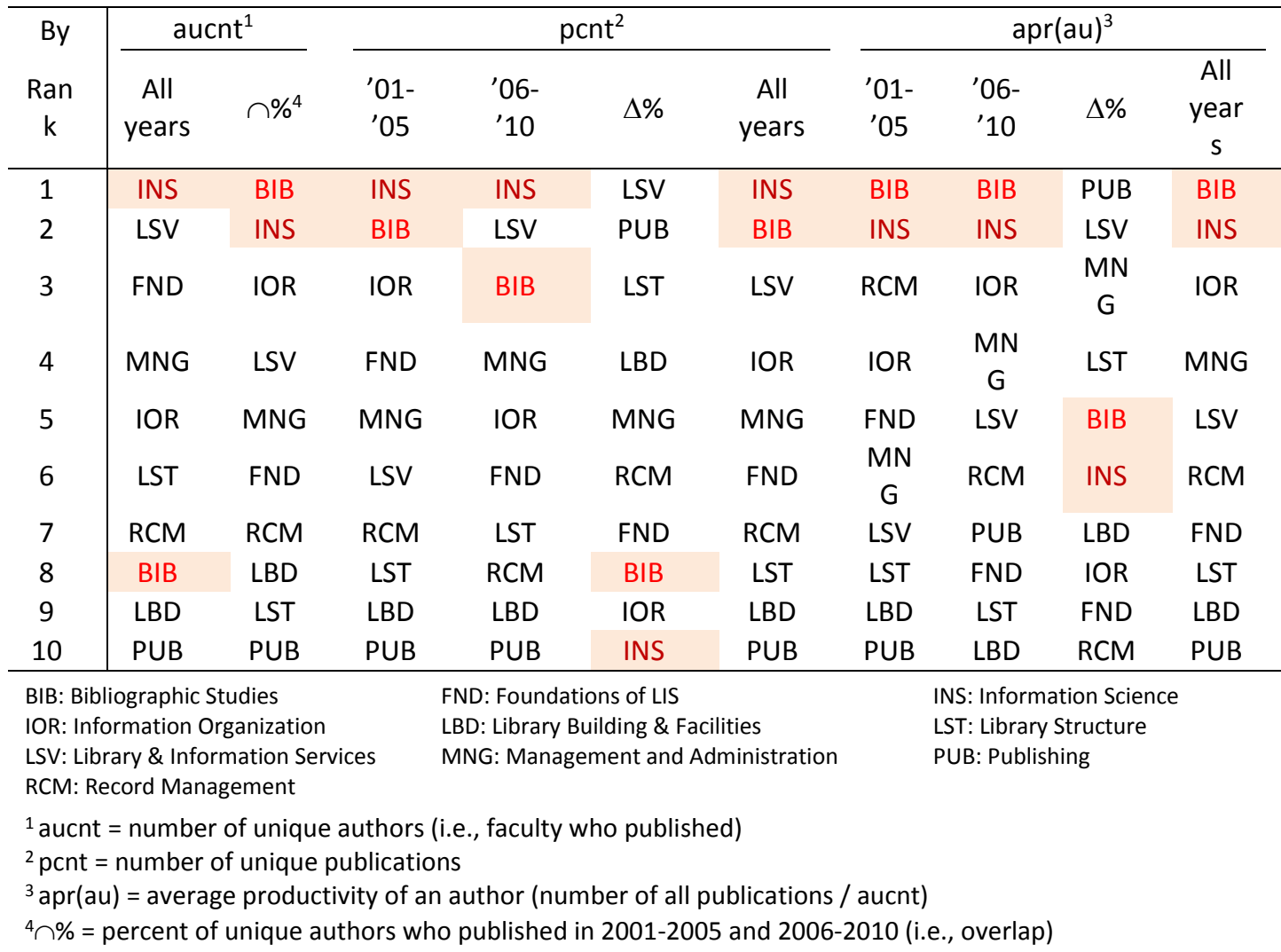

Table 4, which lists subject area rankings by various measures, displays several interesting patterns. Information Science and Bibliographic Studies, ranked at the top by most measures, were clearly the most productive subject areas. They also appear to be the most stable/established subject areas, as evinced by high author overlap $(\cap \%)$ and small productivity changes over time $(\Delta \%)$. Where Information Science and Bibliographic Studies differed was in popularity, as measured by number of authors who published in subject areas (i.e., aucnt). In contrast to Information Science, which was at the top rank by aucnt, 
Bibliographic Studies was ranked $8^{\text {th }}$ out of 10 subjects. The fact that BIB still ranked near the top by publication count (i.e., pcnt) despite the low author count is a testament to the high productivity of authors in the subject area of Bibliographic Studies.

Citation count. In terms of the total citation count of subject areas, Information Science (INS) was the most frequently cited area with 2,047 citations (Table 5). The papers on average were cited two to five times with Record Management (RCM) and Foundations of LIS (FND) at the upper end (4.93 and 4.12) and Bibliographic Studies at the lower end (1.95).

In terms of average citation count over the 5-year time period, the majority of subject areas showed increases in average citation count in the second period, which reflects a definitely expanding impact of the subject areas over time. The decreasing citation counts shown in Library Building \& Facilities (LBD), Library Structure (LST), Library \& Information Services (LSV), and Management and Administration (MNG) may indicate the true decline in impact of these subject areas, or it may reflect the effect of longer cited half-life exacerbated by the citation and data lag. In either case, the data shows definite differences in citation patterns across subject areas over time.

Table 5: Numbers of publication and citation counts by subject areas

\begin{tabular}{|c|c|c|c|c|c|c|c|c|c|}
\hline \multirow[b]{2}{*}{ Subject } & \multicolumn{3}{|c|}{ Publication count } & \multicolumn{3}{|c|}{ Citation count } & \multicolumn{3}{|c|}{ Average citation count } \\
\hline & $\begin{array}{c}\text { '01-'05 } \\
\text { (A1) }\end{array}$ & $\begin{array}{c}\text { '06-'10 } \\
\text { (A2) }\end{array}$ & $\begin{array}{c}\text { All } \\
\text { years }\end{array}$ & $\begin{array}{c}\text { '01-'05 } \\
\text { (B1) }\end{array}$ & $\begin{array}{c}\text { '06-'10 } \\
\text { (B2) }\end{array}$ & $\begin{array}{c}\text { All } \\
\text { years }\end{array}$ & $\mathrm{B} 1 / \mathrm{A} 1$ & $\mathrm{~B} 2 / \mathrm{A} 2$ & $\begin{array}{c}\text { All } \\
\text { years }\end{array}$ \\
\hline BIB & 127 & 157 & 284 & 238 & 316 & 554 & 1.87 & 2.01 & 1.95 \\
\hline FND & 89 & 119 & 208 & 337 & 519 & 856 & 3.79 & 4.36 & 4.12 \\
\hline INS & 251 & 297 & 548 & 896 & 1151 & 2047 & 3.57 & 3.88 & 3.74 \\
\hline IOR & 118 & 140 & 258 & 294 & 392 & 686 & 2.49 & 2.80 & 2.66 \\
\hline LBD & 10 & 17 & 27 & 39 & 61 & 100 & 3.90 & 3.59 & 3.70 \\
\hline LST & 23 & 49 & 72 & 98 & 155 & 253 & 4.26 & 3.16 & 3.51 \\
\hline LSV & 83 & 190 & 273 & 383 & 702 & 1085 & 4.61 & 3.69 & 3.97 \\
\hline MNG & 87 & 145 & 232 & 368 & 480 & 848 & 4.23 & 3.31 & 3.66 \\
\hline PUB & 1 & 2 & 3 & 3 & 7 & 10 & 3.00 & 3.50 & 3.33 \\
\hline RCM & 34 & 47 & 81 & 137 & 262 & 399 & 4.03 & 5.57 & 4.93 \\
\hline Total & 823 & 1163 & 1986 & 2793 & 4045 & 6838 & 3.39 & 3.48 & 3.44 \\
\hline
\end{tabular}

Interestingly, the two most productive subject areas Information Science (INS) and Bibliographic Studies (BIB) were ranked low in terms of average impact (Table 6). Information Science, despite having the most citations, ranked only 4th in average impact per paper due to the large pcnt of 548, which is almost twice the pcnt (284) of the second most productive subject area (i.e., Bibliographic Studies). Bibliographic Studies, which had relatively low citation count to begin with (6th in all time periods), had the smallest average impact of all subject areas.

Low impact scores of Bibliographic Studies, along with its high productivity, reflect the characteristics of a subject area with prolific authorship but "narrow" impact patterns. Bibliographic Studies research in Korea, which involves enumeration and description of old texts, is a type of field that calls for solitary investigations that are artifact-driven. The field is dominated by a few prominent scholars with largely distinct areas of expertise, whose works are based on diverse sets of artifacts. Consequently, researchers in Bibliographic Studies, with a "narrow" pool of prior research to cite from and the penchant for engaging in investigation of new artifacts rather than extending existing work, tend to cite less

Page | 76 
frequently than authors in other subject areas. The low number of citations may also reflect the tendency of authors in Bibliographic studies to cite more books than journal articles (Lee and Lim 2002).

Table 6: Subject area rankings by publication and citation counts

\begin{tabular}{|c|c|c|c|c|c|c|c|}
\hline \multirow[b]{2}{*}{ Rank } & \multirow{2}{*}{$\begin{array}{c}\text { pcnt }^{1} \\
\text { All years }\end{array}$} & \multicolumn{3}{|c|}{$\mathrm{ccnt}^{2}$} & \multicolumn{3}{|c|}{$\operatorname{aim}(p)^{3}$} \\
\hline & & '01-'05 & '06-'10 & All years & $\begin{array}{l}\text { '01- } \\
\text { '05 }\end{array}$ & '06-'10 & All years \\
\hline 1 & INS & INS & INS & INS & LSV & $\mathrm{RCM}$ & $\mathrm{RCM}$ \\
\hline 2 & BIB & LSV & LSV & LSV & LST & FND & FND \\
\hline 3 & LSV & MNG & FND & FND & MNG & INS & LSV \\
\hline 4 & IOR & FND & MNG & MNG & $\mathrm{RCM}$ & LSV & INS \\
\hline 5 & MNG & IOR & IOR & IOR & LBD & LBD & LBD \\
\hline 6 & FND & $\mathrm{BIB}$ & $\mathrm{BIB}$ & $\mathrm{BIB}$ & FND & PUB & MNG \\
\hline 7 & $\mathrm{RCM}$ & LST & $\mathrm{RCM}$ & $\mathrm{RCM}$ & INS & MNG & LST \\
\hline 8 & LST & $\mathrm{RCM}$ & LST & LST & PUB & LST & PUB \\
\hline 9 & LBD & LBD & LBD & LBD & IOR & IOR & IOR \\
\hline 10 & PUB & PUB & PUB & PUB & BIB & BIB & BIB \\
\hline
\end{tabular}

${ }^{1} \mathrm{pcnt}=$ number of unique publications

${ }^{2} \mathrm{ccnt}=$ number of unique citations

${ }^{3} \operatorname{aim}(p)=$ average impact of a paper (ccnt/pcnt)

A Kruskal-Wallis $\mathrm{H}$ test was conducted to determine if there were differences in citation counts across subject areas. The distribution of citation counts were statistically different between subject areas, $\chi^{2}(9)=95.431, p<.001$. Post hoc analysis using a Bonferroni correction for multiple comparisons revealed that papers about Bibliographic Studies were cited significantly less often than those addressing Foundations of LIS, Library Building \& Facilities, Library Structure, Management and Administration, Library \& Information Services, Information Organization, Information Science, and Record Management at $p<$ .001. Moreover, papers about Information Organization were cited significantly less often than papers related to Library \& Information Services and Record Management at $p<.001$.

\section{DISCUSSION}

Regarding the question of which subject areas of LIS were popular (i.e., publication count) and influential (i.e., citation count) in Korea between 2001 and 2010, our study findings showed that the area of Information Science was the most popular and influential in terms of the publication and citation counts in the past ten years. The study also found that popularity and impact of subject areas were changing between 2001 and 2010. For example, while there were no notable changes in the popularity (i.e., publication count) of Information Organization and Bibliographic Studies during the 10-year time window looked at, Library \& Information Services, Library Structure, and Management and Administration drew a lot of attention in the recent five years (2006-2010) (Table 3); however, the impact of research as measured by citation counts of the papers published in those areas were shown to have declined, suggesting that increased popularity and/or productivity of research areas do not necessarily guarantee higher research impact.

With respect to the impact of research in subject areas in the past ten years, Information Science received the highest citation counts in total. However, research in Record 
Management received the highest average citation count per publication, followed by Foundations of LIS, Library \& Information Services, and Information Science, which suggests that the overall impact of a subject area may not always coincide with the quality of individual articles in that area. Another noticeable point is that the average citation rate (i.e., citation count per publication) of Information Organization and Bibliographic Studies remained consistently low across the years, which may reflect the different citation patterns in those research areas. In 2006-2010, Foundations of LIS and Record Management received relatively more citations than other areas, reflecting the possibility of temporal changes in citation impact of subject areas.

We also found differences in publication and citation rates among subject areas, answering the second research question of whether there are any differences in the publication and citation rates of papers among subject areas. What then are the causes of citation differences in subject areas? According to the normative theory on citing behavior, such differences may reflect the differences in quality or impact of research across subject areas as citations reflect "intellectual or cognitive influence on scientific work" (Bornmann and Daniel 2008, p. 48). However, from the perspective of social constructivists who argue that diverse factors exert influence on citing behavior (Bornmann and Daniel 2008), the citation differences may not be solely caused by quality but influenced by social, political, and economic factors. Furthermore, some other extrinsic factors, such as author-, article-, or journal-level attributes, could be associated with citations (Judge et al. 2007; Peng and Zhu 2012). Therefore, given that we do not have clear understanding of researchers' citing behavior in each subject area, there should be a cautious interpretation of citation differences.

In the evaluative bibliometrics, especially within a single discipline, researchers might be more likely to take the normative approach rather than social constructivist approach. In that regard, the study findings raise the question of whether or not applying the normative approach to evaluate research performances in LIS in Korea is valid. In particular, the study found that the authors in Bibliographic Studies, who were almost twice as productive (i.e., publications) as authors in other subject areas, received the lowest citation counts. We posit that the low number of citations to articles does not reflect the quality or impact of research in subject areas with distinctive research scope such as Bibliographic Studies as evidenced by a prior study by Lee and Lim (2002), who found the tendency of authors in Bibliographic Studies to cite more books than journal articles. In addition, our findings that showed increasing trends in average citation count in six of the ten subject areas and decreasing trends in the rest of areas in the recent five years might not simply be explained by the quality differences. These imply the different citing behaviors of authors across subject areas even within the single discipline, not just across disciplines, which may cause the differences in citation counts across the subject areas of LIS.

\section{LIMITATIONS AND CONCLUSIONS}

Since the study used the publication and citation data of LIS faculties in Korea, the findings of the study may not be generalized to LIS in other countries or to other disciplines. Despite the limitations, we have observed the publication and citation trends of LIS papers in Korea for the past decade and found evidences of differences in bibliometric patterns across subject areas that argue against a uniform approach to research evaluation. By examining the publication and citation patterns across subject areas of LIS papers and observing the possible effect of sub-disciplinary culture on citing behaviors, the study 
demonstrated the need for subject-specific assessment of multidisciplinary research discipline such as LIS. Subject-specific assessments of research performance, especially in terms of bibliometric analysis, require not only subject-specific rubrics but also an understanding of research pattern differences across subject areas that enable proper interpretations of data.

\section{ACKNOWLEDGEMENT}

This research received no specific grant from any funding agency in the public, commercial, or not-for-profit sectors.

\section{REFERENCES}

Abbasi, A., Altmann, J. and Hwang, J. 2010. Evaluating scholars based on their academic collaboration activities: Two indices, the RC-index and the CC-index, for quantifying collaboration activities of researchers and scientific communities. Scientometrics, Vol.83, no.1: 1-13.

Adkins, D. and Budd, J. 2006. Scholarly productivity of U.S. LIS faculty. Library \& Information Science Research, Vol.28, no.3: 374-389.

Blessinger, K. and Hrycaj, P. 2010. Highly cited articles in library and information science: An analysis of content and authorship trends. Library \& Information Science Research, Vol.32, no.2: 156-162.

Borgman, C.L. (Ed.) 1990. Scholarly communication and bibliometrics. Newbury Park, CA: Sage.

Bornmann, L. and Daniel, H.D. 2008. What do citation counts measure? A review of studies on citing behavior. Journal of Documentation, Vol.64, no.1: 45-80.

Brinn, T., Jones, M.J. and Pendlebury, M. 2000. Measuring research quality: Peer review 1 , citation indices 0. Omega-International Journal of Management Science, Vol.28, no.2: 237-239.

Brooks, T.A. 1985. Private acts and public objects: An investigation of citer-motivation. Journal of the American Society for Information Science, Vol.36, no.4: 223-229.

Budd, J.M. and Seavey, C.A. 1996. Productivity of U.S. library and information science faculty: The Hayes study revisited. Library Quarterly, Vol.66, no 1: 1-20.

Castellano, C. and Radicchi, F. 2009. On the fairness of using relative indicators for comparing citation performance in different disciplines. Archivum Immunologiae et Therapiae, Vol.57, no.2: 85-90.

Cronin, B. 2005. The reward system. In The Hand of Science: Academic writing and its rewards. Lanham, MD: Scarecrow Press: 117-137.

Cronin, B. and Meho, L.I. 2006. Using the $h$-index to rank influential information scientists. Journal of the American Society for Information Science and Technology, Vol.57, no.9: 1275-1278.

Cronin, B. and Meho, L.I. 2008. Applying the author affiliation index to library and information science journals. Journal of the American Society for Information Science and Technology, Vol.59, no. 11: 1861-1865.

Davarpanah, M.R. and Aslekia, S. 2008. A scientometric analysis of international LIS journals: Productivity and characteristics. Scientometrics, Vol.77, no.1: 21-39.

De Bellis, N. 2009. Bibliometrics and citation analysis: From the Science Citation Index to cybermetrics. Lanham, MD: Scarecrow Press. 
Hayes, R.M. 1983. Citation statistics as a measure of faculty research productivity. Journal of Education for Librarianship, Vol.23, no.3: 151-172.

Jarvelin, K. and Vakkari, P. 1990. Content analysis ofresearch articles in library and information science. Library and Information Science Research, Vol.12, no.4: 395-421.

Judge, T.A., Cable, D.M., Colbert, A. and Rynes, S.L. 2007. What causes a management article to be cited-article, author, or journal? Academy of Management Journal, Vol.50, no.3: 491-506.

Korevaar, J.C. and Moed, H.F. 1996. Validation of bibliometric indicators in the field of mathematics. Scientometrics, Vol.37, no.1: 117-130.

Landis, J.R. and Koch, G.G. 1977. The measurement of observer agreement for categorical data. Biometrics, Vol.33, no.1: 159:174.

Lee, J. and Choi, W. 2013. Difference in citation rates by subject areas of LIS in Korea. Proceedings of the American Society for Information Science and Technology, Vol.50, no.1: 1-4.

Lee, J. and Yang, K. 2011. A bibliometric analysis of faculty research performance assessment methods. Journal of the Korean Society for Information Management, Vol.28, no.4: 119-140.

Lee, L.-J. and Lim, J.-H. 2002. A study on the research trends of bibliography in Korea. Journal of Korea Library and Information Science Society, Vol.33, no.1: 323-344.

Li, J.A., Sanderson, M., Willett, P., Norris, M. and Oppenheim, C. 2010. Ranking of library and information science researchers: Comparison of data sources for correlating citation data, and expert judgments. Journal of Informetrics, Vol.4, no.4: 554-563.

Norris, M. and Oppenheim, C. 2010. Peer review and the $h$-index: Two studies. Journal of Informetrics, Vol.4, no.3: 221-232.

Osareh, F. 1996. Bibliometrics, citation analysis and co-citation analysis: A review of literature 1. Libri, Vol.46, 149-158.

Oh, S.-H. 2005. A study on the research trends of library \& information science in Korea by analyzing journal articles and the cited literatures. Journal of the Korean Society for Information Management, Vol.22, no.3: 379-408.

Park, J.-H. and Song, M. 2013. A study on the research trends in library and information science in Korea using topic modeling. Journal of the Korean Society for Information Management, Vol.30, no.1: 7-27.

Peng, T.-Q. and Zhu, J.J.H. 2012. Where you publish matters most: a multilevel analysis of factors affecting citations of internet studies. Journal of the American Society for Information Science and Technology, Vol.63, no.9: 1789-1803.

Pritchard, A. 1969. Statistical bibliography or bibliometrics?. Journal of Documentation, Vol.25, no.4: 348-349.

Radicchi, F., Fortunato, S. and Castellano, C. 2008. Universality of citation distributions: Toward an objective measure of scientific impact. Proceedings of the National Academy of Sciences of the United States of America, Vol.105, no.45: 17268-17272.

Rinia, E.J., van Leeuwen, T.N., van Vuren, H.G. and van Raan, A.F.J. 1998. Comparative analysis of a set of bibliometric indicators and central peer review criteria. Evaluation of condensed matter physics in the Netherlands. Research Policy, Vol.27, no.1: 95-107.

Saracevic, T. 1999. Information science. Journal of the American Society for Information Science and Technology, Vol.50, no.12: 1051-1063.

Smith, L. C. 1981. Citation analysis. Library Trends, Vol. 30, no. 1: 83-101.

Slyder, J.B., Stein, B.R., Sams, B.S., Walker, D.M., Beale, J., Feldhaus, J.J. and Copenheaver, C.A. 2011. Citation pattern and lifespan: a comparison of discipline, institution, and individual. Scientometrics, Vol.89, no.3: 955-966. 
Walters, W.H. and Wider, E.I. 2015. Disciplinary, national, and departmental contributions to the literature of library and information science, 2007-2012. Journal of the Association for Information Science and Technology (Advance online publication).

Wu, D., He, D., Jiang, J., Dong, W. and Vo, K. 2012. The state of iSchools: an analysis of academic research and graduate education. Journal of Information Science, Vol.38, no.1: 15-36.

Yang, K. and Lee, J. 2012. Analysis of publication patterns in Korean library and information science research. Scientometrics, Vol.93, no.2: 233-251.

Yang, K. and Lee, J. 2013. Bibliometric approach to research assessment: Publication count, citation count, \& author rank. Journal of Information Science Theory and Practice, Vol.1, no.1: 27-41.

VanRaan, A.F.J. 2006. Comparison of Hirsch-index with standard bibliometric indicators and with peer judgment for 147 chemistry research groups. Scientometrics, Vol.67, no.3: 491-502.

Vieira, E.S. and Gomes, J.A.N.F. 2010. Citations to scientific articles: Its distribution and dependence on the article features. Journal of Informetrics, Vol. 4, no.1: 1-13. 